\title{
Organizational Effectiveness: Collaboration in an Integrated Project Team
}

\author{
Bakker H L M*, Wang F, Bosch-Rekveldt G C M and Eykelenboom M \\ Department of Civil Engineering, Delft University of Technology, Netherland
}

Submission: February 06, 2018; Published: April 05, 2018

*Corresponding author: Bakker H L M, Professor management of Engineering Projects, Delft University of Technology, 2628 CN Delft, Stevinweg

1, Netherland, Tel: +31 15 2784893/+31 65512 66 46; Email: H.L.M.Bakker@tudelft.nl

\begin{abstract}
Projects in the process industry are getting more complex from a technical as well as an organizational point of view. These projects can be considered as series of multi-phase and multi-discipline design and engineering activities involving contributions from many parties on many locations. In order to successfully perform such projects collaboration is required. This paper presents the results of studying a refinery revamp project. In this project the opportunity was offered to investigate the collaboration in the project team. Objective was to study the effectiveness of the organization in a multi-actor, multi-office and multi-discipline environment and identify potential areas for improving the collaboration. The method chosen was to study the business process model and combine this with a social network analysis (SNA) via observations, surveys and interviews. The differences shown in the comparison between the SNA and the business process model indicated areas where the collaboration could be improved. Furthermore, early identification of potential overload of people has been discovered from the social network analysis. SNA showed to be a powerful analysis method for investigating softer factors in projects, which is not yet common practice in the process industry.
\end{abstract}

Keywords: Social network analysis; Multi-actor; Multi-office; Dispersed execution; Contractor-client interaction; FEED phase; Collaboration; Business process modeling

Abbreviations: SNA : Social Network Analysis; FEED: Front-End Engineering and Design; PFD: Process Flow Diagram; P\&ID: Process and Utility Instrumentation Diagrams; WBS: Work Breakdown Structure; PAM: Project Activity Model; PRC: Project Requirement Checklist; WBS: Work Breakdown Structure; SBET: Site Based Engineering Team

\section{Introduction}

Over the years projects in the process and energy industry are getting bigger and more complex. But unfortunately the performance of these projects is lagging behind. Various publications highlight this disappointing performance of large and megaprojects in the industry [1] and more specifically in the Oil \& Gas industry [2]. This is not a trend from the last couple of years, but already a long-standing issue in the field of project management. As early as 1987, Morris and Hough analyzed 3500 projects from all over the world executed in the period from 1959 till 1984 [3]. They came to the staggering conclusion that these projects showed typical overruns in expenditure and schedule between 40 and 200\% (and bigger overruns have been seen). Today, almost 30 years later, the situation has not really improved.

The potential solutions that most practitioners and researchers are proposing are: more attention to early involvement of all parties concerned [4], a seamless collaboration between owner and contractor (a real integrated team), giving attention to the development of real collaborative relationships and spending sufficient time on the front-end development of the project [5].

Knowing these areas for improvement is one thing, acting on it, as recent history shows, is still considered a challenge. For a project that was recently initiated for the revamp of a refinery in Western Europe of one of the large multinational oil companies (= owner), a single engineering contractor (= contractor) has been selected to perform the front-end engineering and design (FEED) phase and the management of the construction phase (EPCm). The managements of both parties have decided to deliver both phases as integrated as possible with a single team consisting of both owner and contractor representatives. Doing this, the intent was to form a high performing team by giving focused attention to the way the team is organized: improving the organizational effectiveness of the combined team. This refinery project is facing a tight schedule with design works carried out in parallel i.e. overlap in definition and execution phases. A separate challenge comes from the complexity of the 
project team formation. It has the work distributed over the Amsterdam and the New Delhi offices of the contractor and the owner team is spread over the US headquarters, the contractor's office in Amsterdam and the refinery site office. In order to take on these challenges and to meet the demanding project schedule, this supportive research was proposed.

This research is part of a longitudinal study into the organizational effectiveness of a project team consisting of owner and contractor. During the course of the project, in all phases of its lifecycle, a number of master students will be embedded in the project team to study the collaboration within the team and between the various locations. In each phase and each year a different master student will participate. This article is the first report out of the research performed by the students over the years.

The aim of the research is to improve collaboration among different disciplines, different actors as well as different offices. It is an empirical study in which the project team is followed and observed initially during the FEED phase.

The workflow methodology will be used for all three levels of collaboration (amongst different disciplines, amongst different actors and amongst different offices). First a business process model will be derived for the present phase of the project. However, the network relationship information, which is extracted from the workflow, only tells what is the expected relationship according to the work procedure. It basically only tells how the organization is supposed to work (=SOLL). The real network relations in an organization may differ and may contain more informal, untracked links, which cannot be observed from workflow and the formal organization chart (=IST). Therefore, Social Network Analysis is invoked to provide a view of the real network within the project team.

Comparing the outcomes of the workflow methodology and the Social Network Analysis can give more insights for and about the team and answer the question how the collaboration and consequently the organizational effectiveness can be (further) improved. The research question that will be answered is therefore "Can a comparison of the theoretical workflow with the real network relations identify shortcomings in the effectiveness of the organization?" The objective of the integrated project team, consisting of owner and main contractor, was to find ways to enhance the collaboration between both parties and in this way to develop and further improve the effectiveness of the project organization.

\section{Literature Review}

\section{Workflow methodology and business process management}

The Workflow Handbook [6] defines workflow as: "The automation of a business process, in whole or part, during which documents, information or tasks are passed from one participant to another for action, according to a set of procedural rules." From a higher-level perspective, workflow can be regarded as a representation of real work, in other words serving as a virtual representation of actual work [7]. In recent research, many people consider Business Process Management (BPM) to be the extension of the workflow theory of the 1990's, which brings process awareness to the strategic and operational level [8]. Business process management consists of an explicit description and representation of the coordination, optimization, and automation of the enterprise assets and tasks-whether internal or external - that make up an enterprise's business processes [9].

A business process is usually specific to a particular project, but it may follow a standard pattern used by the company [10]. Within the engineering disciplines for this particular downstream oil project in this phase, this corresponds to the tracking of tasks and sub-tasks according to the Work Breakdown Structure in order to deliver the final design or product. The flow being described may refer to a document, service or product that is being transferred from one step to the next.

Design processes in chemical and process engineering are hard to support. This is especially true for the conceptual design and basic engineering, in which the fundamental decisions concerning the plant design are taken. The design process is highly creative, many design alternatives are explored, and both unexpected and planned feedback occurs frequently [11]. Previous research [12] pointed out a way of improving collaboration in the chemical and process industry by examining the workflow dependency and improving the associated information exchange process. Schneider and Marquardt [13] (regarded workflow as one of the three perspectives (next to software and product data) in the design life cycle concept for the chemical engineering projects and provided systematic information support for interdisciplinary collaboration.

Sidhu and Volberda [14] conducted research on a globally distributed team using the same workflow concept. They found that due to the nature of tasks and the associated differences in employee competencies, home offices and distributed offices perform different value-chain activities. Similarly, Joshi and his team adopted workflow and network methodology to prioritize the main conflicts and problems in multinational companies [15].

Among many workflow and BPM research papers, there are few related to process industry. In the white paper of Best Practices in Front-End Design [16], a rough FEED workflow is formulated which shows the main line of activities for developing a plant design. Even though this figure is mapped in a very high level manner, it still shows that by using deliverables (documents) like Process Flow Diagram (PFD), Process and 
Utility Instrumentation Diagrams (P\&IDs), Datasheets, Plant Layout, Capital Expenditure estimates, the design and decision making process can be shown with a simple time sequence.

When checking the latest business process methodology $[17,18]$, it shows a trend to start focusing on "people" and consequently the workflow system is re-positioned as a tool for organizational performance studies. Strong belief is that there is a link between the workflow-performers and the social network relationships, which reflect the collaborative team behavior and has high impact on business success. Battsetseg et al. [17] summarized that most of the workflow models employ several essential entity-types (modeling components): activity, role, performer, application amongst others. The activities always have corresponding roles and performers. Therefore, the dependency and links among the tasks in the workflow actually bring together the performers in a network relation with links representing the dependencies. Song et al. [18] found out that 'the workflow management systems are 'people systems' that must be designed, deployed, and understood within their social and organizational contexts."

Lewis et al. [19] analyzed the interests and goals of different stakeholders (actors) since these provide the specifications and requirements for the activities. In the adaptive workflow theory, the stakeholder is an important factor making the workflow more dynamic. Therefore, this research will also start from the workflow point of view and broaden this methodology to study the collaboration among project disciplines, globally distributed offices and involved actors as a whole.

\section{Social network analysis}

Social Network Analysis (SNA) is a powerful tool from an organizational perspective [20]. It has drawn a variety of scholarly pursuits throughout the years and its implementation developed over time. SNA has been applied in various research domains such as collaboration, partnership, knowledge sharing and innovation, corporate acquisitions, social media, political parties, criminal psychology, healthy habits, disease spread [2126]. Social network analysis aims to describe the relationships between people as complete as possible. It includes relationships maintained in digital computer mediated interactions, or the communication, activity for resource allocation, problem solving that is needed for work. A so-called Sociogram in which vertices represent individuals visualizes the results of SNA. It is a good way to discover the informal structure within an organization, which coexists with the formal structure usually stated in the organization chart. Besides, SNA can be used to study the cooperative relationships across organizational boundaries: outsourcing, joint ventures, alliances, globally distributed teams [27]. Social network information can be gathered via electronic platforms such as email, forums and social media. However, most often the information is gathered manually. Manual collection includes observation and recording of activities, questionnaires or surveys, holding interviews and reviewing diaries.
Social network analysis has its limitations. One major drawback is that the result is difficult to judge or to interpret. Especially because SNA is very unique, every network being studied is different in team size, composition, location, and type of relation. It is very difficult to have a generalized benchmark that tells what a social network should look like. Therefore, the workflow methodology is adopted here as a supplemental method which provides some work-related insights and can be used to interpret the result of the social network analysis.

\section{Research Methodology}

This research will investigate the abstract term collaboration by attaching it to the visible workflow chain and using the organization chart as resource to link the people with their functions and positions. Starting from the main FEED deliverables, this research will check how the deliverables are divided into manageable tasks (the Work Breakdown Structure or WBS) and how these deliverables are produced, issued and reviewed by involving the different actors (this is what is called the workflow). In phase 1 the Practices, Guidelines, Manuals, Checklists, Templates, Project Debriefs from both the owner and the contractor will be studied. Based on the findings, the network relations in the taskforce will be modelled. Every workflow is restrained between clear start and end points. This is usually dependent on the scope of work. During this research, the project tracked is carrying out the Front End Engineering Design (FEED) of a refinery revamp project. The scope of work for this FEED package will be the scope of the workflow model. Besides this scope, the flow model is composed of many elements. There are various types of workflow models that have been proposed in the workflow literature and almost all employ five essential entity-types [28]:

- Activities in a design process and their interdependencies;

- Information produced during the activities or needed for their execution;

- Roles or organizational units of the actors;

- $\quad$ Resources needed to complete the tasks;

- $\quad$ Tools required for performing the activities.

Other factors like time, knowledge repository, locations and flow flexibility are also covered in the literature. The work process models to be created during the modeling sessions must have sufficient entity types to provide the information relevant for reaching the research goal. In this research, the workflow model is serving as a base for deriving the network relations. Therefore, the composition elements that will be chosen are: the activities and order, the information flow (input and output) and the actors. The tools, resources and the time factors will not be considered. This will lead to a theoretical workflow model, based on the desired information flow. 


\section{Civil Engineering Research Journal}

The second part of the research, phase 2, is to check the real network existing in the taskforce by carrying out a Social Network Analysis (SNA): identifying how the information is really flowing. The Social Network Analysis will be designed based on Cross \& Parker's network theory [29]. To visualize the results Node XL has been used. The data will be quantitatively examined on individual level from the aspects of degree centrality, betweenness centrality and eigenvector centrality [30]. These aspects are defined as follows. Degree centrality is a simple count of the total number of connections linked to a vertex. Betweenness centrality is an indicator of a node's centrality in a network. It is equal to the number of shortest paths from all vertices to all others that pass through that node. A person with few connections could have a high eigenvector centrality if those few connections were themselves very well connected.

There are several data collecting methods for social network analysis. Ideally, network approaches tend to study the whole population by means of census, rather than by sample [31]. Therefore, at one side of the spectrum of approaches is the "full network" method, which requires collecting information from all actors. This approach yields the maximum of information, but can also be costly in terms of time and effort. Since there is no definite limit to the number of people who are interrelated, full network is in any case not practically possible. In this research, the snowball method is selected [31], since the research has a relatively limited target group: the project team. Therefore, the ties among people in the company but not working on this project will not be studied. The snowball sampling approach Table 1: Relationship types examined via the survey [29]. which is modified for use in this network analysis is as follows: the first round initial participants are all project members in Amsterdam office, including team members from different engineering disciplines, support and administration staff, management team as well as the owner representatives. The subjects are encouraged to name their colleagues in New Delhi and in the USA office. Responses from the above-mentioned key actors are further used to select a second round of participants, limited to those who have been identified by two or more firstround participants. The "two or more" technique is adopted from a network study from Smythe, et al. [32].

There are many types of relations that can be studied in network research. For instance, people can be asked to name the person who helps them solve problems or the person who helps career development. Therefore, different questions can reflect different aspects of how people are connected to each other. In the book The Hidden Power of Social Networks by Cross and Parker [29] a thorough framework covering different aspects of surveying social networks is presented that provides good foundation for this research. Considering that the aim of this research is to improve the work-related collaboration for a particular project, the survey design should focus on the work process of the project taskforce. Moreover, the aspects to be examined should be consistent with the aspects derived from the workflow procedure study. According to the conclusions from the previous paragraph and combining them with organizational chart information, the collaborative aspects used in the current study are presented in Table 1.

\begin{tabular}{|c|c|}
\hline Work Related Interactions & Description \\
\hline Input gathering & $\begin{array}{l}\text { In a daily work life, people start their work by gathering the input resources, tools and task descriptions from } \\
\text { their peers and then they can conduct their part of work. }\end{array}$ \\
\hline Problem solving & $\begin{array}{l}\text { When people encounter any problems, they may need to discuss with their co-workers who work on the similar } \\
\text { subject or people from other disciplines if the problem is relevant. }\end{array}$ \\
\hline Decision Making & $\begin{array}{l}\text { When people encounter a situation, which they need to make a decision, if they don't have the authority, they } \\
\text { may need to report to their supervisor or search for people who they know possess the expertise, which can be } \\
\text { relied on. }\end{array}$ \\
\hline Output distributing & $\begin{array}{c}\text { After they produce and complete their part of work, the task is transferred to the next person for completing } \\
\text { other aspects or reviewing. }\end{array}$ \\
\hline Recognition & $\begin{array}{l}\text { When the work is successful done and distributed to the next information user, people may need to be given } \\
\text { feedback for their job and be recognized for their hard work. }\end{array}$ \\
\hline
\end{tabular}

Apart from the work-related interactions mentioned in Table 1 , which are the visible aspects of relationships, previous social network research discovered that social network analysis could also seek to reflect the invisible motor and knowledge sharing behind the interaction process. The elements that should be considered in this respect are knowledge awareness (who has the skill and or expertise) [27,33], accessibility (the willingness to share that knowledge) [27,34-36] and trust (your confidence in the knowledge that you received) [37].
In phase 3 the results of the workflow model will be compared with the outcomes of the social network analysis and this will lead to recommended improvements to the organizational effectiveness in phase 4.

The research methodology and the various steps followed as described in the previous in the previous paragraph is schematically shown in Figure 1. 


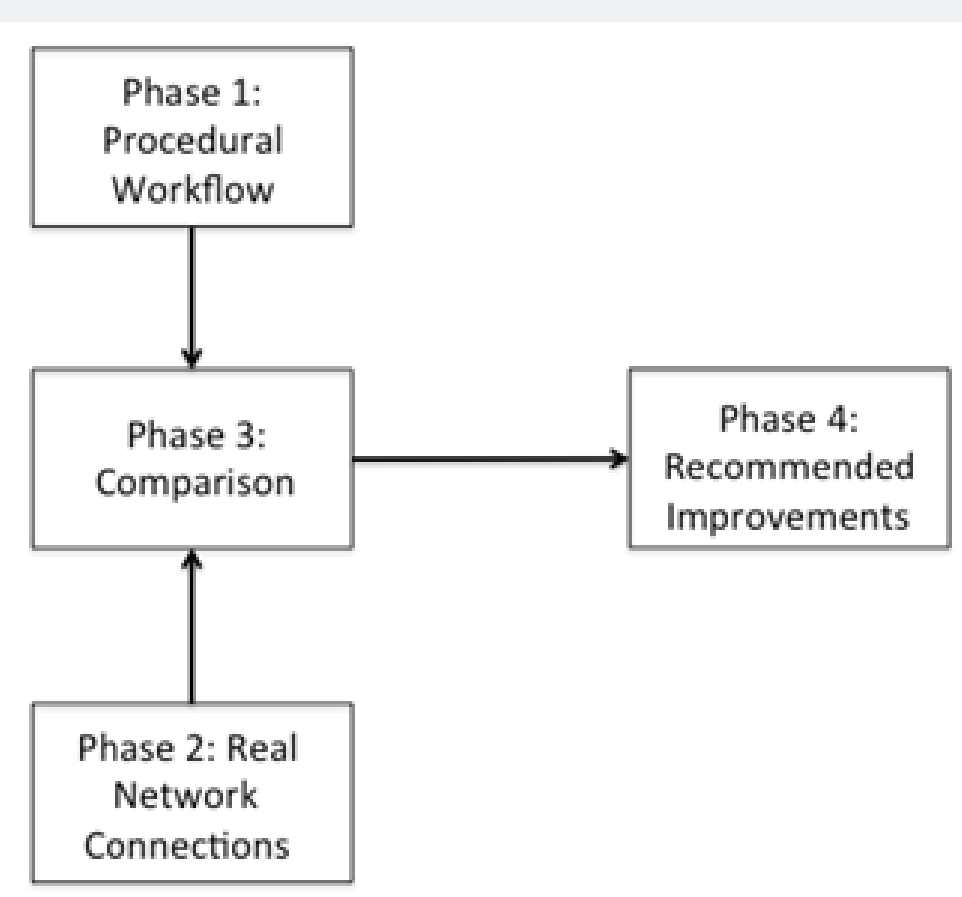

Figure 1: Schematic diagram showing the research approach followed

\section{FEED Business Process Model}

\section{Workflow model}

The FEED phase entails the work required to produce process and engineering documentation in sufficient quality and depth so as to adequately define the project requirements for detailed engineering, procurement and construction and to support a rough project cost estimate. The FEED package could be used as the basis for bidding the execution phase contracts and is used as the design basis. A good FEED should reflect all the owner's project specific requirements and avoid significant changes during the execution phase. For large sized projects, FEED contracts usually take around one year to complete. During the FEED phase, close communication between owner, operators and engineering contractor is needed to work out the project specific requirements [38]. Owner's time saving strategy resulted in contractor being both the FEED and the EPC contractor. Since Contractor will also carry out the EPC, there is no bidding procedure in between. The FEED package will mainly be used as the design basis for detailed engineering design and estimation for the investment.

Deliverables are the output from one stage and the input to the next stage. Deliverables are always the communication media and the checking points between disciplines, owner and contractor in engineering work processes. FEED deliverables are often handled not as single instances but in the form of documents, which act as carriers for the design data and will be reviewed, approved and transferred to the EPC phase. These documents differ widely in form and content, ranging from word documents, reports, job bulletins, datasheets and calculations to documents containing graphical data or even digital models.

Based on both contractor's standards and owner's requirements, a list of main FEED deliverables for this particular project has been defined. In the business process model for the FEED only the deliverables, which are necessary for the end product/project design have been taken into account. Other project deliverables (such as Project Execution Plan, Refinery Reconfiguration Plan and Project Master Schedule) will not be investigated. After choosing the main FEED deliverables and taking the dynamics of documentation into consideration, the next step is to model the workflow based on the standard project execution procedure. The method that is used to gather the model input information is a company document study. The Project Activity Model (PAM) with associated Activity Plans, Project Requirement Checklist (PRC), Project Work Breakdown Structure (WBS) and other practices for each discipline are examined in order to derive at the activity sequences and identify the actors involved.

All these three main documents: PAM, WBS and PRC provide holistic information to understand the FEED activity and its actors. However, none of them show the sequential relation visually. PRC is a checklist and mainly focusing on describing a clear scope for a particular project. WBS divides the FEED package into manageable tasks but only has the links of activity in vertical/hierarchical level. PAM contains the information for the sequence and dependency of the tasks, but not presenting them in a graphical manner since the activities are not linked via 
lines. Besides, the whole PAM system is too complex, includes all the activities and is not project specific. For study purposes, a simplified workflow will be derived based on PAM, PRC and WBS, and focusing on the FEED deliverables.

The whole workflow of the major FEED deliverables is shown in Figure 2 with each block representing a deliverable or a task with on the top the responsible discipline. There are three types of dependencies shown in the model. One-way arrows represent the sequential dependency. Two-way arrows in orange show the mutual dependency, which means that there is an iterative and interactive process when developing both deliverables. The third type of dependency is the circular dependency shown, for example, between the P\&IDs and the HAZOP study. The HAZOP study is performed based on P\&ID while also going back to P\&ID development. The design specifications from the owner are the starting point of the whole model. The contractor promotes optimum interaction between the owner and the contractor team on a daily basis. The premise is that close contact and coordination between discipline leads from the owner and the contractor will facilitate and enhance the project execution. More specifically, in the team formation and organizational structure, the contractor team is set up in order to mirror owner's organization to streamline the communication channels between counter-parts.

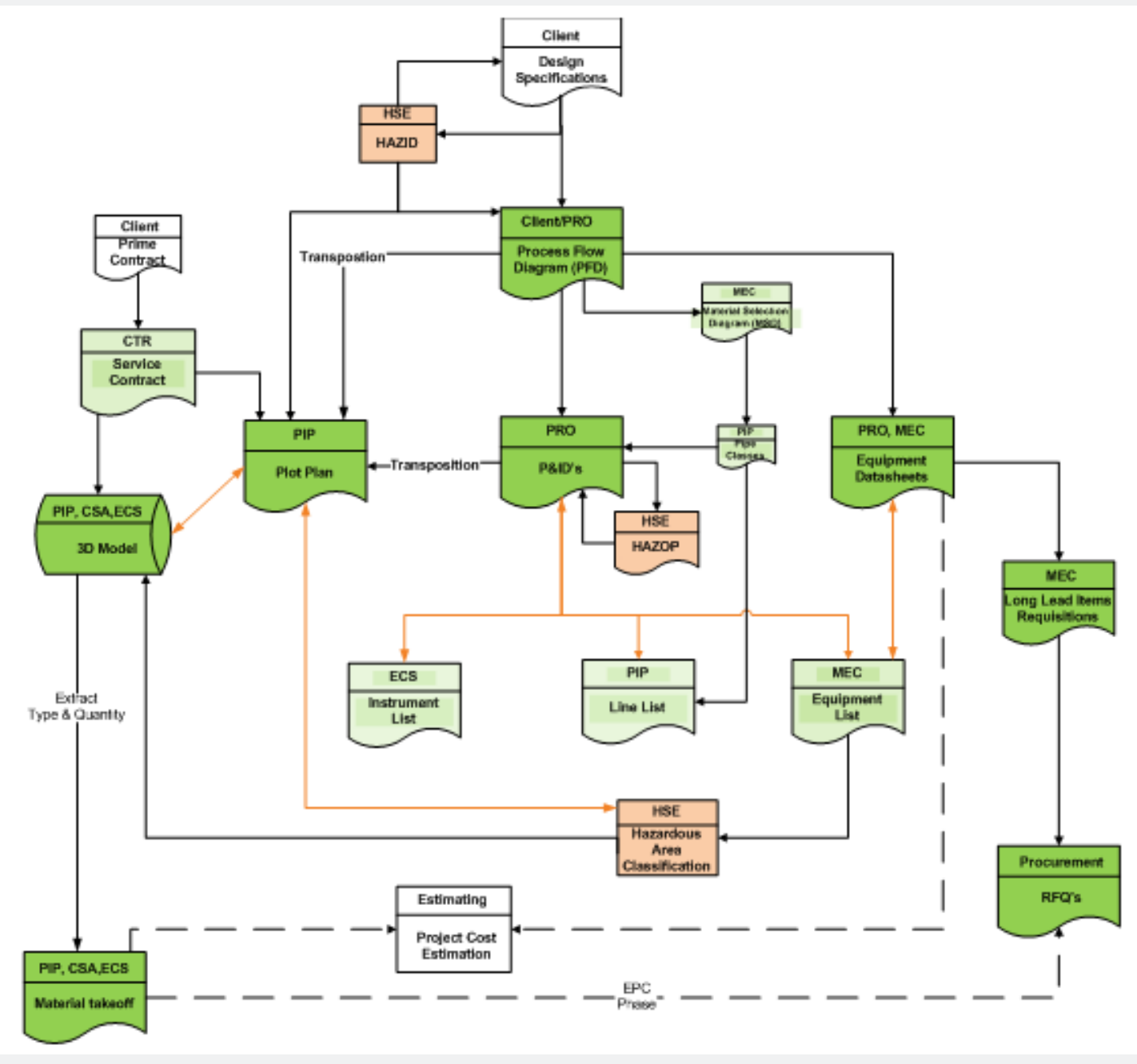

Figure 2: The general workflow model as derived from the company document study

All the roles and responsibilities are aligned with contractor's standard execution model for the FEED stage. Engineering disciplines such as mechanical, piping and civil report to the engineering manager, while process is a separate discipline and reports to its own process manager.

\section{Multi-locations}

There are four offices involved in the FEED phase. The Amsterdam office is the leading design office of the contractor. Owner representatives are located together with contractor staff in the Amsterdam office and formed up teams of counterparts 


\section{Civil Engineering Research Journal}

in order to improve the team integration. The Amsterdam office has connections to the other three offices. The USA office is the main design \& engineering office of the owner during the FEED phase. The decision makers and gatekeepers of this project are in this office and they pay close attention to the schedule and cost. This office assigns design engineers as representatives to the Amsterdam office. Therefore, at discipline level, the management team, project control team, process and engineering disciplines from the USA office have contacts with Amsterdam as well as the refinery site. Also representatives from the refinery operations department were present in the Amsterdam office. At the refinery site office, the owner's operations and maintenance team is located. This team mainly consists of process engineers, equipment engineers, electrical engineers and business supporting staff. As a European subsidiary, this office has contacts with the main office in the USA. At the start of this study, the Site Based Engineering Team (SBET) is just formed and is located directly at the site office. Refinery site office has contact with both Amsterdam office and the USA office, especially for the activities related to the revamp task. The New Delhi shares the work with Amsterdam office in almost all the engineering disciplines, especially the disciplines involved for developing 3D model (piping, electrical and civil). Because the revamp part of work is not shared with New Delhi, this office has no direct contact with the refinery site office or the owner in the USA office. Using the organization charts of both the owner's and contractor's team together with the business process model, all relations have been tracked down and summarized in Table 2 .

Table 2: Discipline interaction matrix in the SOLL situation. Value 1: connections expected; Value 0: no/very few connections expected. *Abbreviations are explained in Appendix A.

\begin{tabular}{|c|c|c|c|c|c|c|c|c|c|c|c|c|c|c|c|c|c|}
\hline & $\stackrel{5}{8}$ & $\sum_{U}^{U}$ & ఝ్ & 뜬 & ⿹弋工 & $\sum_{i=1}$ & 뗖 & 留 & $\Xi$ & u & 主 & $\bar{a}$ & 音 & $\sum_{0}$ & 茴 & $\begin{array}{l}\text { \& } \\
\stackrel{*}{\alpha}\end{array}$ & $\approx$ \\
\hline${ }^{*}$ AUT & 1 & 0 & 0 & 0 & 0 & 1 & 0 & 0 & 0 & 0 & 0 & 1 & 0 & 0 & 0 & 0 & 0 \\
\hline CMC & & 1 & 1 & 1 & 0 & 1 & 0 & 0 & 0 & 1 & 0 & 0 & 0 & 1 & 1 & 0 & 1 \\
\hline CSA & & & 1 & 1 & 1 & 1 & 0 & 1 & 0 & 1 & 1 & 1 & 1 & 0 & 0 & 0 & 1 \\
\hline CTR & & & & 1 & 0 & 1 & 0 & 0 & 0 & 1 & 0 & 0 & 1 & 1 & 1 & 0 & 0 \\
\hline ECS & & & & & 1 & 1 & 1 & 1 & 0 & 1 & 1 & 1 & 1 & 0 & 1 & 1 & 1 \\
\hline EM & & & & & & 1 & 1 & 1 & 1 & 1 & 1 & 1 & 1 & 1 & 1 & 1 & 1 \\
\hline HSE & & & & & & & 1 & 1 & 0 & 0 & 1 & 0 & 1 & 0 & 0 & 1 & 1 \\
\hline MEC & & & & & & & & 1 & 0 & 1 & 1 & 1 & 1 & 0 & 1 & 1 & 1 \\
\hline PA & & & & & & & & & 1 & 0 & 0 & 0 & 0 & 1 & 0 & 0 & 0 \\
\hline PC & & & & & & & & & & 1 & 0 & 0 & 1 & 1 & 1 & 1 & 1 \\
\hline PDDM & & & & & & & & & & & 1 & 1 & 1 & 1 & 0 & 1 & 0 \\
\hline PI & & & & & & & & & & & & 1 & 1 & 1 & 0 & 1 & 0 \\
\hline PIP & & & & & & & & & & & & & 1 & 0 & 0 & 1 & 1 \\
\hline PM & & & & & & & & & & & & & & 1 & 1 & 1 & 1 \\
\hline PR & & & & & & & & & & & & & & & 1 & 0 & 0 \\
\hline PRO & & & & & & & & & & & & & & & & 1 & 1 \\
\hline RS & & & & & & & & & & & & & & & & & 1 \\
\hline
\end{tabular}

Based on the workflow and the organizational arrangement, it can be expected that most frequent contacts should happen in process and project control. People from these disciplines are expected to adapt to the owner company culture quickly and be able to interpret and transfer the information accurately and efficiently to other disciplines. From the workflow chart in Figure 2 , process discipline is the first one to take the initiative for the FEED activities. This discipline has to fulfill the specific role to translate the job requirements into specific scoping deliverables for the other engineering and supporting disciplines. A close cooperation between the process discipline and the owner organization is therefore inevitable. Considering the fact that the contract type is reimbursable, the owner pays close attention to the cost, schedule and change orders via project control discipline. Therefore, there are many owner representatives from project control located directly in Amsterdam office together with contractor team and they have frequent and extensive communication with each other. Besides, these owner representatives need to keep the senior managers from the US office well informed of the progress. Therefore, this discipline also will have more contact with US office. 


\section{Civil Engineering Research Journal}

\section{Three levels of interaction}

The first outcome is a workflow model in Figure 2 that depicts the main work related activities, their sequence and interdependencies as well as the responsible disciplines. The results of the network information in this chapter are clustered on three levels:

Discipline coordination level: Visually, the workflow model shows that the process discipline is the initial discipline, which has to translate the design specifications to scope of work for other disciplines. At the same time, it takes over the design \& engineering work from the owner and keeps on developing the PFDs and P\&IDs. These are the basic deliverables for the FEED. Therefore, process discipline is the key player in the project. Other engineering disciplines follow directly after process and provide input for the supporting disciplines like project control, procurement and contracting.

Office work sharing level: Amsterdam office is expected to connect with all other three offices. New Delhi office mainly connects to Amsterdam office. USA office, Refinery Site office and Amsterdam office are expected to be connected to each other.

Owner team integration level: The organization structures, team compositions from both owner and contractor are investigated as well as the counterpart relations. Close contact is expected to be in the process and project control discipline.

All the network relations derived represent the SOLL (=as it should be) situation. These are not the optimized but the expected relationships for the project taskforce. In the following paragraphs carrying out a social network analysis will discover the real network relations (=IST).

\section{The Real Social Network}

In order to investigate the actual relationships a Social Network Analysis has been executed for which a survey has been designed. In a social network survey, the responses can be gathered in several ways. Ticking the names from a list of the persons the respondents have relations with, giving a score or ranking, or giving a value assessment of their perceived contact level with each person. By far the most common approach to scale (assigning numbers to) relations is to simply distinguish between relations being absent (coded 0 ), and ties being present (coded 1). The result of this measurement is shown in $0 / 1$ mode and therefore is called binary scale measurement [29]. The binary measurement method has been chosen for this survey because of its simplicity.

Kossinets [39] assessed the impact on the structural properties of social networks of three kinds of missing data: network boundary specification (non-inclusion of actors or affiliations), survey non-response, and fixed choice design (a list of names is given already). He concluded that setting the network boundary too narrow and giving a fixed list of names to choose from can influence the network structure greatly since some names will not be mentioned, potentially resulting in stochastic omission of some fraction of actors from the network. As explained, the targeted survey subjects are all members of the project team, wherever their location. Open questions were formulated, asking the respondents to nominate people instead of choosing from a predefined list. The non-response effect is generally relatively small in network analysis. When the survey asks actors to name peers with whom they interact, the nonresponse effect can be balanced out by reciprocal nominations [40].

The social network survey is launched by using the snowball method with the first round carried out in the Amsterdam office to 110 people. 80 of them responded. Hence the first round response rate is $73 \%$. The second round is launched to 23 people, located in the USA, New Delhi and Refinery Site office. 7 of them responded. This accounts for $30 \%$ of the targeted second round group. The total number of participants is 87 . Through these participants, 163 people are discovered and mapped in the network. The respondents as well as the entire network discovered are characterized as a diverse population representing a range of discipline expertise from both owner and contractor. Most of the engineering disciplines participated well in the survey. Some management and supporting disciplines have actively participated. The owner and contractor participation distribution is consistent with the spread in the organization: the owner accounts for $39 \%$ and contractor accounts for $61 \%$ of respondents. Therefore, the participants sufficiently represent the whole team.

For confidentiality reasons, code numbers have replaced the names of the participants. Each code number starts with the discipline abbreviation followed by a number. The entire social network for the project is depicted in Figure 3, with nodes (vertices) representing actors and ties (edges) representing connections between them. Each circle represents a discipline. The actors are connected within each circle and also with actors from other circles. The most connected discipline is automatically placed in the centre. The social network analysis result is mapped by using no arrow (undirected) ties. It is the overview covering all the relationship types: information input-output, problem solving, decision-making and recognition in line with Table 1. There are in total 163 people (vertices) discovered in the whole network and 769 relationships (edges) are mentioned of which 224 are two-way confirmed answers (duplicate edges) and 545 are one-way mentions (unique edges). After merging the duplicate edges, the total number of connections discovered is 657 .

From the overview map in Figure 3, it is difficult to see that all disciplines are connected to each other, what can be seen is that the process and other engineering activities are well connected. No isolated islands exist at the disciplinary level. Process discipline is in the centre and taking the leading role fulfilling FEED design work. On the individual level, this general overview also reflects that no single individual is isolated. 


\section{Civil Engineering Research Journal}

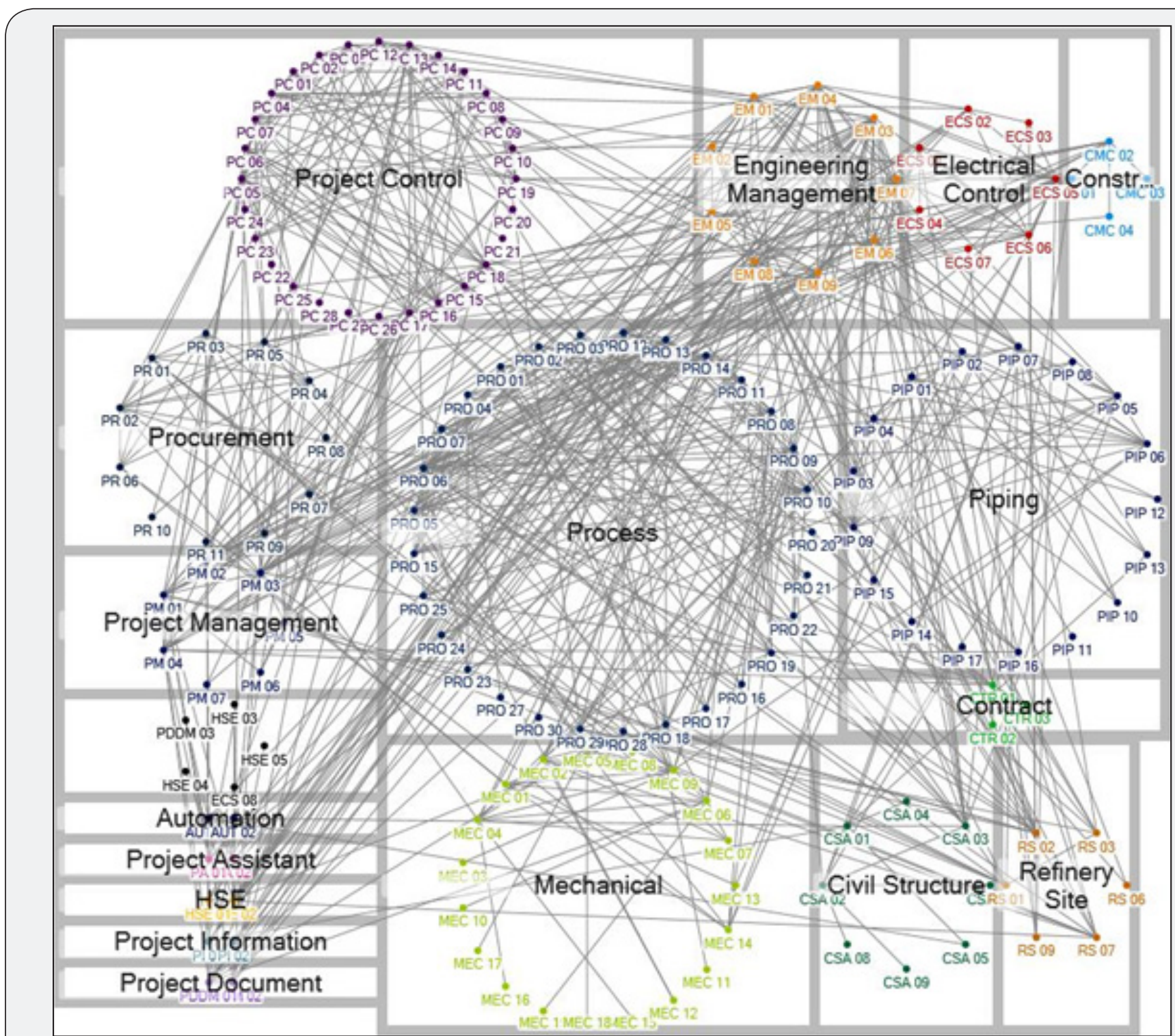

Figure 3: Sociogram of the reported connections in the integrated project team.

However, it can be found that some disciplines include more outliers than others. In the civil structure circle and mechanical circle, there are several people being mapped by only holding one connection to the rest of the group. When tracking back to the function of these outliers, it can be found that they are most often subject matter specialists who work in more projects at the same time and are not physically located with the project team. They serve more in an advisory capacity than being responsible for the task. In other cases, for engineering management, process, piping and project control disciplines, each individual is more actively connected. No significant spread is seen in the number of connections of individual members of one group. Each circle on the overview map can be regarded as a sub-graph and can be separately studied. That will show the connections within one single discipline. It is assumed that people who work on similar tasks have more interactions than those who work on different topics.
Process discipline is highly intra-connected with each person having on average connections with 3 people in the same discipline. Among other engineering disciplines, piping is most connected with each person being connected to approximately 2 people in the same discipline. Mechanical and piping have a similar size of group (19 and 17 people, respectively) but the mechanical discipline is less intra-connected even with two more people. The same can be seen when comparing the electrical control department with civil structure, where civil is clearly less connected. This result is very logical for mechanical, considering their specialty on different kinds of equipment (from heat exchanger to furnace, from reactor to compressor). They are very much focused on their own area of work and are educated in specialized areas. While, in process or piping, people usually have the same kind of knowledge. It is easier and more necessary for them to transfer and exchange knowledge with their discipline. The project control and engineering 


\section{Civil Engineering Research Journal}

management disciplines also have high intra-connecting scores, around 3 people/person, which means that these two disciplines are very well integrated as a group.

The connections among different disciplines can be shown graphically (Figure 4), a graph that is less cluttered, but it is probably more clearly shown in a quantitative way in a matrix. The matrix in Table 3 shows how many connections are mentioned by the respondents clustered by discipline. It also includes the internal connection within one discipline in the diagonal line. The larger the number of connections is, the stronger the link and more frequent the communication between the disciplines.

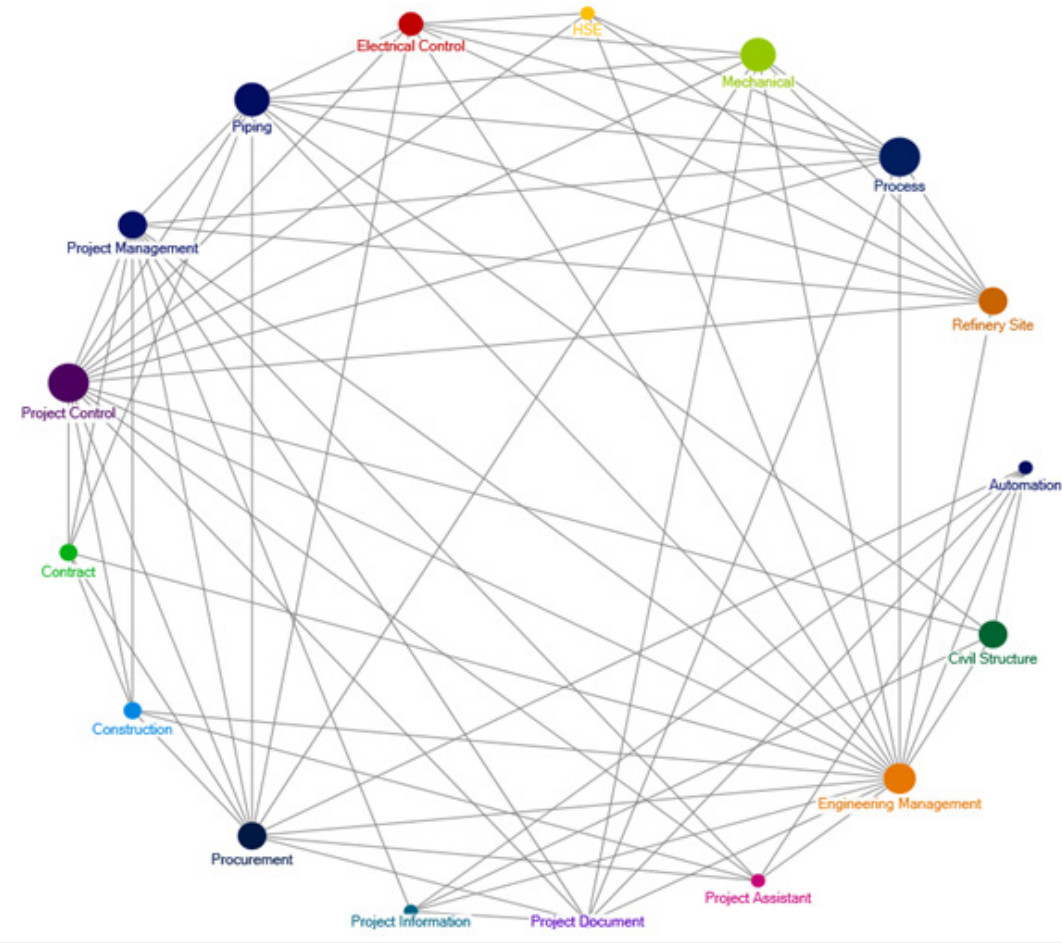

Figure 4: Inter-disciplinary Sociogram in IST situation.

Table 3: Disciplinary interaction matrix (blank means no connection).

\begin{tabular}{|c|c|c|c|c|c|c|c|c|c|c|c|c|c|c|c|c|c|}
\hline & AUT & CMC & CSA & CTR & ECS & EM & HSE & MEC & $\mathbf{P A}$ & PC & PDDM & PI & PIP & PM & PR & PRO & RS \\
\hline AUT & & & 2 & & & 1 & & & 2 & & 2 & 2 & & & 1 & & \\
\hline CMC & & 4 & & 1 & & 6 & & & 1 & 4 & & & & 6 & 1 & & \\
\hline CSA & & & 8 & & & 6 & & & & 3 & & 1 & 7 & & & & \\
\hline CTR & & & & 2 & & 2 & & & & 2 & & & 1 & 2 & 2 & & \\
\hline ECS & & & & & 10 & 7 & 1 & 3 & & 4 & & & 1 & & 1 & 9 & 5 \\
\hline EM & & & & & & 24 & 4 & 9 & 3 & 14 & 10 & 4 & 20 & 22 & 2 & 9 & 9 \\
\hline HSE & & & & & & & 3 & & & 1 & & & & & & 5 & 1 \\
\hline MEC & & & & & & & & 25 & & 2 & 2 & & 5 & & 11 & 8 & 3 \\
\hline PA & & & & & & & & & 1 & 1 & & & & 6 & 1 & & \\
\hline PC & & & & & & & & & & 88 & 3 & & 3 & 20 & 9 & 6 & 3 \\
\hline PDDM & & & & & & & & & & & 1 & 1 & & 2 & 1 & 2 & \\
\hline PI & & & & & & & & & & & & & & 1 & & & \\
\hline PIP & & & & & & & & & & & & & 32 & 1 & 1 & 12 & 3 \\
\hline PM & & & & & & & & & & & & & & 11 & 3 & 5 & 2 \\
\hline PR & & & & & & & & & & & & & & & 21 & & \\
\hline PRO & & & & & & & & & & & & & & & & 93 & 17 \\
\hline RS & & & & & & & & & & & & & & & & & 1 \\
\hline
\end{tabular}




\section{Civil Engineering Research Journal}

As can be seen there are many empty cells which might represent missing connections. However, to accurately analyze this matrix, the no-connection judgment should not be made directly based on the visualized results. It is not always necessary, nor desirable, to connect all the disciplines together. Only when it is necessary according to the
Work-related procedure, should two disciplines have connections. Too many connections will bring an overload of information and thus decrease the productivity. Therefore, this matrix provides a very good overview of the IST situation, which can now be compared with Table 2 representing the SOLL situation derived from the workflow study to find the structural gaps and missing links. This comparison is provided in Table 4.

Table 4: Missing links (Red Cross), unexpected links (red numbers) and insufficient connections (yellow fields). The numbers in the top row and left column are representing the size of the groups.

\begin{tabular}{|c|c|c|c|c|c|c|c|c|c|c|c|c|c|c|c|c|c|c|}
\hline $\begin{array}{c}\text { Group } \\
\text { Size }\end{array}$ & & 2 & 4 & 8 & 3 & 8 & 9 & 5 & 19 & 2 & 28 & 3 & 2 & 17 & 7 & 11 & 29 & 6 \\
\hline & AUT & CMC & CSA & CTR & ECS & EM & HSE & MEC & PA & PC & PDDM & PI & PIP & PM & PR & PRO & RS & \\
\hline 2 & AUT & $\mathrm{X}$ & & 2 & & & 1 & & & 2 & & 2 & 2 & & & 1 & & \\
\hline 4 & CMC & & 4 & $X$ & 1 & & 6 & & & 1 & 4 & & & & 6 & 1 & & $X$ \\
\hline 8 & CSA & & & 8 & $\mathrm{X}$ & $x$ & 6 & & & & 3 & $\mathrm{X}$ & 1 & 7 & & & & $\mathrm{X}$ \\
\hline 3 & CTR & & & & 2 & & 2 & & & & 2 & & & 1 & 2 & 2 & & \\
\hline 8 & ECS & & & & & 10 & 7 & 1 & 3 & & 4 & $\mathrm{X}$ & $X$ & 1 & & 1 & 9 & 5 \\
\hline 9 & EM & & & & & & 24 & 4 & 9 & 3 & 14 & 10 & 4 & 20 & 22 & 2 & 9 & 9 \\
\hline 5 & HSE & & & & & & & 3 & $\mathrm{X}$ & & 1 & $\mathrm{X}$ & & $\mathrm{X}$ & & & 5 & 1 \\
\hline 19 & MEC & & & & & & & & 25 & & 2 & 2 & $X$ & 5 & & 11 & 8 & 3 \\
\hline 2 & PA & & & & & & & & & 1 & 1 & 1 & & & 6 & 1 & & \\
\hline 28 & PC & & & & & & & & & & 88 & 3 & & 3 & 20 & 9 & 6 & 3 \\
\hline 3 & PDDM & & & & & & & & & & & 1 & 1 & $\mathrm{X}$ & 2 & 1 & 2 & \\
\hline 2 & PI & & & & & & & & & & & & $\mathrm{X}$ & $\mathrm{X}$ & 1 & & $\mathrm{X}$ & \\
\hline 17 & PIP & & & & & & & & & & & & & 32 & 1 & 1 & 12 & 3 \\
\hline 7 & PM & & & & & & & & & & & & & & 11 & 3 & 5 & 2 \\
\hline 11 & PR & & & & & & & & & & & & & & & 21 & & \\
\hline 29 & PRO & & & & & & & & & & & & & & & & 93 & 17 \\
\hline 6 & RS & & & & & & & & & & & & & & & & & 1 \\
\hline
\end{tabular}

When only the links between owner and contractor are studied, it is again clear that the process discipline is very well connected both internally with owner staff within the process circle and externally with owner staff from other disciplines. Similarly, contractor's engineering management, electrical control system, mechanical and project control disciplines are very well integrated with the owner team. From this analysis can be seen that the piping department has no internal connections: piping staff are mostly connected with the owner staff from mechanical, process, engineering management and refinery site. Given the fact that the project team will roll over to EPC phase when piping discipline plays a more central role, the ownercontractor integration in this particular discipline should be an area of attention.

Apart from mapping the connections nominated by the taskforce, respondents were also asked for missing links. As a response the owner process engineers indicated that they wished to have more direct contact with contractor staff in the New Delhi office. On discipline level, a very distinguishing result is that many disciplines stressed to have more interactions with the refinery site. Second finding is that project engineers proposed to have more connections with HSE. Project control staff indicated that they would like to get more help from the engineering disciplines to help understand scope of work and work sequence.

The quantitative analysis aims at identifying individual network influences on the whole project team. There are four parameters that will be measured in the study [30]:

- Degree centrality: directly contact numbers

- Betweenness centrality: bridge scores between people

- Closeness centrality: distance scores for broadly connected people

- $\quad$ Eigenvector centrality: influence scores for strategically connected people

Except for the degree centrality, for which the absolute value directly indicates the number of connections; other centralities are better to be interpreted using the ranking and relative value instead of the absolute value. Figure 5 shows degree centrality on the $x$-axis, betweenness centrality on the $y$-axis and the node 
size represents the closeness centrality. Since the quantitative method is mainly suitable for individual network influence study, this research also focuses on evaluating and discovering the most centralized staff. Besides, considering the role and function of each individual, special focus is given to the lead engineers and the management team members, who are coloured green (=contractor leads) and blue (=owner leads). The red nodes are common staff.

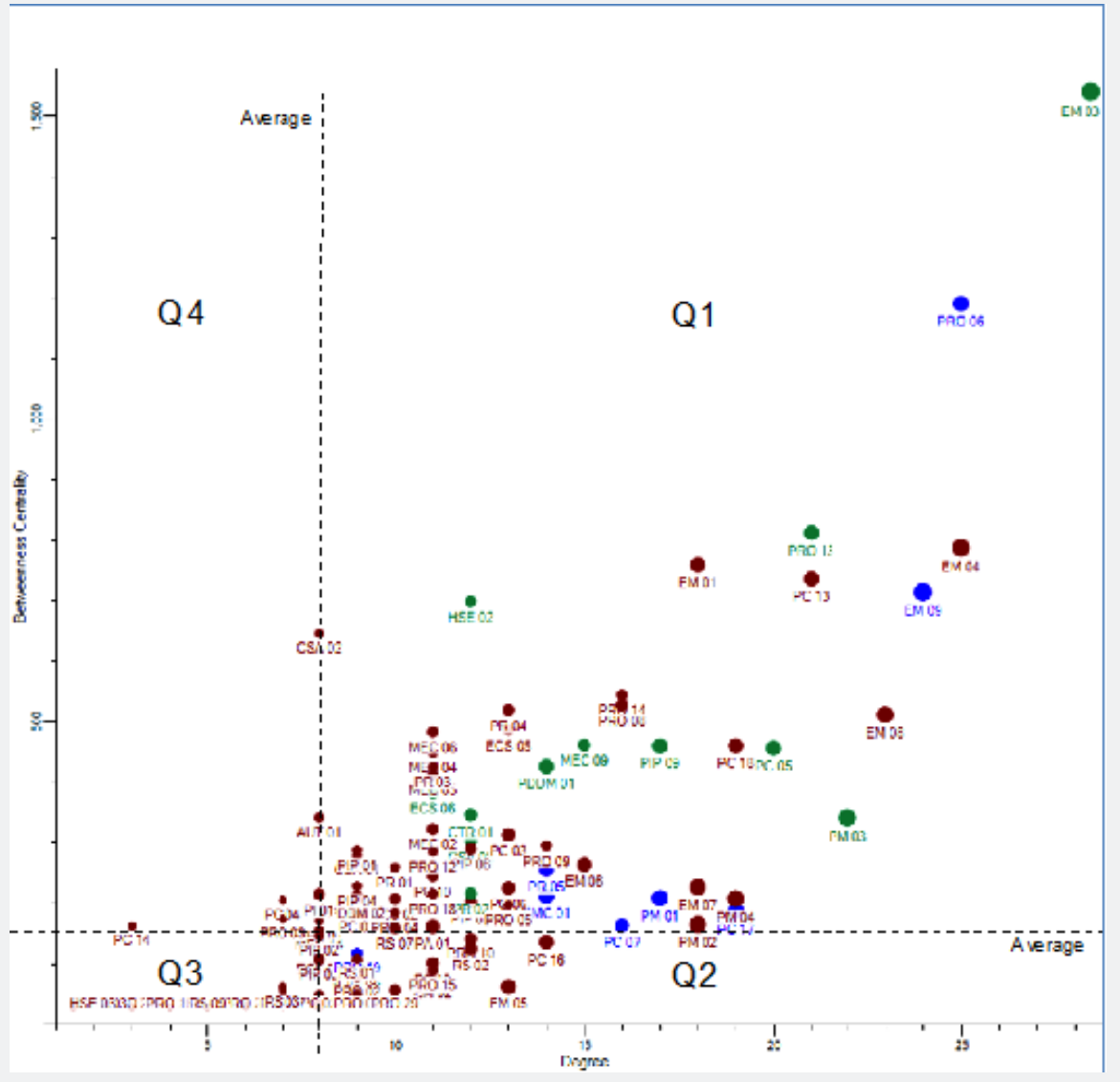

Figure 5: Centrality results on individual level. X-axis represents degree centrality, Y-axis betweenness centrality. The size of the balls stands for closeness centrality. Green balls are contractor leads, blue balls client leads, red balls normal project staff.

Two lines, representing the averages, split the whole graph into four quadrants. The people who are shown in the first quadrant have relatively high betweenness centrality and degree (above the average level). It can be noticed that most of the discipline leads from contractor and owner belong to this category. Logically, there is almost no one in the fourth quadrant (Q4) since without possessing a number of direct contacts it is not easy to be acting as a bridge between people. The left bottom quadrant (Q3) contains the outliers of the network; this group actually contains quite an amount of people. However, in the graph, the nodes with same value are covered by each other. People in the right bottom quadrant (Q2) are active networkers because they have above average direct contacts. Supporting and management actors (EM, PM and PC) are in this category and are actively engaged networkers indicating that they facilitate the process, but without them, the real engineering work can still be achieved.

The degree of centrality (vertex) is a count of the number of unique edges that are connected to it. The higher the numbers of ties an actor has, the more influential he or she may be. The average degree centrality of studied participants is 8 . By checking the $\mathrm{x}$-axis on Figure 5, EM03 has the highest degree centrality score: 29 direct connections. PRO06 and EM04 have the same degree centrality: 25. EM03 is the engineering manager from contractor side.PRO06 is a lead process design engineer from the owner and EM0 4 is a project engineer from the owner. EM03 and PR006 also largely exceed the second level of high betweenness centrality: PR013, EM04, EM09, PC13. This indicates that these two actors really develop their function role as much as possible as manager and lead engineer and they have high potential of interpersonal skills. This can also indicate that the network is highly dependent on these two central actors. Any job changes happening to these key actors may influence the connectivity for the project team at least for a short period.

Betweenness centrality is a measure of how often a given vertex lies on the shortest path between two other vertices. More generally, vertices that are included in many of the shortest paths between other vertices (called geodesic distances) have a 
higher betweenness centrality than those that are not included on such paths. A node with high betweenness centrality has a large influence on the transfer of items through the network, under the assumption that item transfer follows the shortest paths. This can be thought of as a kind of "bridge" score, a measure of how much the removal of a person would disrupt the connections between other people in the network. The idea of brokering is often captured in the measure of betweenness centrality. Therefore, networks that have individuals with high betweenness are vulnerable to having information flows disrupted by power plays or key individuals leaving.

Closeness centrality is a measure indicating the social distance. The higher this value is, the more influential a person is considering the distance he/she needs to get connected to others. One property of closeness centrality is that individuals who are highly connected to others within their own cluster tend to have a high closeness centrality [41]. For this centrality value, many people are having the same highest score value. Among them, the engineering discipline leads from mechanical, piping, civil are found as well as the process leads. This result indicates the lead engineers fulfill their network functions very well in their own disciplines. High centrality/connectiveness might be an indicator for overload of an individual.

Eigenvector centrality is a more sophisticated view of centrality: a person with few connections could have a very high eigenvector centrality if those few connections were themselves very well connected. Eigenvector centrality allows for connections to have a variable value, so that connecting to some vertices has more benefit than connecting to others. Similar to degree, eigenvector centrality extends itself to calculate how "connected" are the nodes connected to you. Therefore, usually highly connected individuals within highly interconnected clusters have high eigenvector centrality [41]. In the social network analysis result (Figure 3) engineering management, project management, process and project control group are very well connected within their own group, and at the same time, very well connected to almost all the other disciplines. Therefore, the calculation result of the highest individual score of eigenvector centrality mostly comes from these three disciplines.

\section{Practical Results}

For practical applications the results from the business process model (SOLL) are compared with the outcomes of the social network survey (IST). The comparison is carried out in two steps:

i. By checking the binary numbers in both situations, the missing links and/or unexpected links can be found and

ii. By checking for existing connections whether the amount is consistent compared to the group size and focusing again on the three levels: discipline, office sharing and contractor-owner integration [42].
On the discipline collaboration level, missing links appear mainly in civil discipline and HSE discipline. Civil is very well connected to piping and project engineers. It is suggested to pay more attention to the work coordination with mechanical and electrical control discipline. In addition, the connection among civil, construction and refinery site needs to be strengthened. Considering the size of the discipline, some connections are mentioned but are identified as not sufficient. Piping and electrical control are expected to have more direct contact with each other instead of through process. From the owner side, there is interaction between procurement and construction, but this link is missing in the contractor team. There are only five connections between process and HSE. It is suggested to promote a way to bring HSE knowledge more to the process design.

On the office collaboration level, even though the four offices are connected as expected in the SOLL situation, the New Delhi office is largely neglected except for the piping discipline. The detailed number of connections reveals more information and it can be seen that even though most of the technical disciplines are mentioned from the New Delhi office, they are usually only mentioned once and only the lead engineer is mentioned. In contrast to other disciplines, piping staff have strikingly more connections with New Delhi. Through observation, it can be found out that the piping lead in Amsterdam office set a very good example by daily communicating with the New Delhi office colleagues. This lead really pays attention to the work sharing and has more personal care for his co-workers in the other offices. It is suggested to take the piping lead as a leading example for other disciplines and pay more attention to and share work with the execution office in New Delhi.

On the owner-contractor team integration level, the process, project control and engineering management team are very well connected to the owner. The piping discipline, even without obvious counterpart, finds its own way to forward their problems and carry out discussion with the owner, mainly through mechanical/project engineers. The interaction at the refinery site is still weak because of the recent set-up of the onsite team [43].

The development of a business process model for a particular project phase in combination with SNA has the potential to improve the effectiveness of integrated project teams. Via the study and the combination of the two methods a number of shortcomings in the project team organization have surfaced. Due to the combination of the models the real time differences compared to the (theoretical) organizational model have helped to further strengthen the team, incorporated people more closely to the team and identified areas that needed more intensive collaboration in order for the integrated team to be as effective as possible. As mentioned in the introduction, this has not been a once-off exercise. The involvement of subsequent students in the project team put the focus on the EPC phase 


\section{Civil Engineering Research Journal}

and subsequently also on the collaboration between the main contractor and their sub-contractors and suppliers [44,45].

\section{Conclusion}

This research innovated the methodology to study a complex project by combining the social network analysis with business workflow modeling forming a SOLL-IST comparison framework. Firstly, this research can be seen as an extension of the business process management methodology. It started by adopting the workflow concept for the process industry. Furthermore, the research focused on the "people" aspect in the workflow and build upon the idea of discovering social networks from the workflow.

The social network analysis was adopted and tailor-made survey questions were developed. In traditional social network analysis, it is difficult to interpret the result, especially, to tell whether a missing link really exists. More background information has to be given in order to judge if a connection is necessary depending on what kind of relations are being studied. That is why in this research the workflow study provides a better base for analyzing and interpreting the social network result.

In addition, this research provided insights into the collaboration in the process industry by targeting the three levels of collaboration that exist in many projects in this industry. It combined the different collaboration themes from the literature study: disciplinary collaboration, globally distributed project team collaboration and client-contractor team integration. This study provides a more holistic view and the findings from this research also showed that these three levels of interaction are very much intertwined and are influencing each other.

The project team has acted on the findings by looking at alleviating the overload on some key players that surfaced during the analysis of Figure 5, and stimulating relationships that have been weak or non-existent. By doing that the coherence between the various locations and disciplines is further improved and the work processes become even more robust and effective. The client and contractor made the deliberate choice, however, that full team integration is not a goal of the project. Too much integration between disciplines could disturb the production machine and construction effectiveness. The research will be continued, however in the EPC phase to further integrate the two teams aimed at successful project completion and subsequently also on the collaboration between the main contractor and their sub-contractors and suppliers.

For the multi-actor study, only owner and contractor have been considered. However, it is suggested to involve the subcontractors and suppliers in the subsequent study during the EPC phase. Another interesting element for future study would be the influence of contract type. The reimbursable nature of the project may lead to more owner staff in the project control discipline in order to keep detailed track of the project cost and schedule.

The overall conclusion is that the development of a business process model for a particular project phase in combination with SNA has the potential to improve the effectiveness of integrated project teams.

\section{Acknowledgement}

This research did not receive any specific grant from funding agencies in the public, commercial, or not-for-profit sectors. The authors are grateful to the project team for their willingness to cooperate in this research.

\section{Appendix A}

\begin{tabular}{|c|c|}
\hline Acronym & Discipline Description \\
\hline AUT & Automation \\
\hline CMC & Construction \\
\hline CSA & Civil Structure \\
\hline CTR & Contract \\
\hline ECS & Electrical Control \\
\hline EM & Engineering Management \\
\hline HSE & Health, Safety and Environment \\
\hline MEC & Project Assistant \\
\hline PA & Project Control \\
\hline PC & Project Document \\
\hline PDDM & Project Information \\
\hline PI & Piping \\
\hline PIP & Project Management \\
\hline PM & Procurement \\
\hline PR & Process \\
\hline PRO & \\
\hline RS & Refinery Site \\
\hline & \\
\hline & \\
\hline
\end{tabular}

\section{References}

1. Merrow EW (2011) Industrial megaprojects: Concepts, Strategies and Practices for Success, John Wiley \& Sons Inc, Hoboken, New Jersey, USA.

2. Ernst, Young (2014) Spotlight on Oil \& Gas megaprojects.

3. Morris PWG, Hough GH (1987) The Anatomy of Major Projects: a study of the Reality of Project Management, John Wiley, Chichester, UK.

4. Suprapto M, Bakker HLM, Mooi HG, Moree W (2014) Sorting out the essence of owner-contractor collaboration in capital projects delivery. International Journal of Project Management 33(3): 664-683.

5. Bosch-Rekveldt MGC (2011) Managing Complex Projects, Dissertation, Delft University of Technology, The Netherlands. 


\section{Civil Engineering Research Journal}

6. Lawrence P, Bouzeghoub M, Fabret F, Matulovic-broqué M (1997) Workflow handbook. Paper presented at the In Proc. Intl. Workshop on Design and Management of Data Warehouses (DMDW'99).

7. Odessa C (2015) Design elements-Workflow diagram 2015.

8. Van Der Aalst WM, Ter Hofstede AH, Weske M (2003) Business process management: A survey Business process management pp. 1-12.

9. Caverlee J, Bae J, Wu Q, Liu L, Pu C, Rouse WB (2007) Workflow management for enterprise transformation. Information, Knowledge, Systems Management 6(1): 61-80.

10. Barga R, Gannon D (2007) Scientific versus business workflows. Workflows for e-Science, pp. 9-16.

11. Nagl M, Westfechtel B, Schneider R (2003) Tool support for the management of design processes in chemical engineering. Computers \& Chemical Engineering 27(2): 175-197.

12. Santos IH, Göbel M, Raposo AB, Gattass M (2004) A multimedia workflow-based collaborative engineering environment for oil \& gas industry. Paper presented at the Proceedings of the 2004 ACM SIGGRAPH international conference on Virtual Reality continuum and its applications in industry.

13. Schneider R, Marquardt W (2002) Information technology support in the chemical process design life cycle. Chemical Engineering Science 57(10): 1763-1792.

14. Sidhu JS, Volberda HW (2011) Coordination of globally distributed teams: A co-evolution perspective on off shoring. International Business Review 20(3): 278-290.

15. Joshi A, Labianca G, Caligiuri PM (2003) Getting along long distance: Understanding conflict in a multinational team through network analysis. Journal of World Business 37(4): 277-284.

16. Patel A (2008) Best Practices in Front-End Design.

17. Battsetseg A, Ahn H, Lee Y, Park M, Kim H, et al. (2013) Organizationa closeness centrality analysis on workflow-supported activity-performer affiliation networks. Paper presented at the $15^{\text {th }}$ International Conference on Advanced Communication Technology (ICACT).

18. Song J, Kim M, Kim H, Kim K (2010) A framework: Workflow-based social network discovery and analysis. Paper presented at the Computational Science and Engineering (CSE), 2010 IEEE 13th Internationa Conference on.

19. Rouse WB, Sage AP (2007) Work, workflow and information systems. Information, Knowledge, Systems Management 6(1): 1-5.

20. Moreno JL (1934) Who shall survive?: A new approach to the problem of human interrelations.

21. Chow WS, Chan LS (2008) Social network, social trust and shared goals in organizational knowledge sharing. Information \& Management 45(7): 458-465.

22. Christakis NA, Fowler JH (2007) The spread of obesity in a large social network over 32 years. New England journal of medicine 357(4): 370 379

23. Klovdahl AS (1985) Social networks and the spread of infectious diseases: the AIDS example. Social science \& medicine 21(11): 1203-1216.

24. Moody J (2004) The structure of a social science collaboration network: Disciplinary cohesion from 1963 to 1999. American sociological review 69(2): 213-238.

25. Rindfleisch A, Moorman C (2001) The acquisition and utilization of information in new product alliances: A strength-of-ties perspective. Journal of marketing 65(2): 1-18.
26. Sparrow MK (1991) The application of network analysis to criminal intelligence: An assessment of the prospects. Social networks 13(3): 251-274.

27. Cross R, Parker A, Borgatti SP (2002) A bird's-eye view: Using social network analysis to improve knowledge creation and sharing. IBM Institute for Business Value, pp: 1669-1600.

28. Eggersmann M, Krobb C, Marquardt W (2000) A language for modelling work processes in chemical engineering. Process Systems Engineering Technical Report LPT-2000-02, RWTH Aachen University.

29. Cross RL, Parker A (2004) The hidden power of social networks: Understanding how work really gets done in organizations: Harvard Business Press.

30. Hansen D, Schneiderman B, Smith MA (2010) Analyzing Social Media Networks with Node XL: Insights from a Connected World, Morgan Kaufmann.

31. Hanneman RA, Riddle M (2005) Introduction to social network methods: University of California Riverside.

32. Smythe TC, Thompson R, Garcia-Quijano C (2014) The inner workings of collaboration in marine ecosystem-based management: A social network analysis approach. Marine Policy 50: 117-125.

33. Eraut M (2000) Non-formal learning and tacit knowledge in professional work. British Journal of Educational Psychology 70(1): 113-136.

34. Astley WG, Sachdeva PS (1984) Structural Sources of Intra organizational: Power: A Theoretical Synthesis. Academy of management review 9(1): 104-113.

35. Burkhardt ME, Brass DJ (1990) Changing patterns or patterns of change: The effects of a change in technology on social network structure and power. Administrative science quarterly 35(1): 104-127.

36. Ibarra H, Andrews SB (1993) Power, social influence, and sense making: Effects of network centrality and proximity on employee perceptions. Administrative science quarterly 38(2): 277-303.

37. Vangen S, Huxham C (2003) Nurturing collaborative relations Building trust in interorganizational collaboration. The Journal of Applied Behavioral Science 39(1): 5-31.

38. EPCengineer (2014) FEED-Front End Engineering Design. Retrieved 15-02, 2015.

39. Kossinets G (2006) Effects of missing data in social networks. Social networks 28(3): 247-268.

40. Stork D, Richards WD (1992) Non-respondents in communication net work studies problems and possibilities. Group \& Organization Management 17(2): 193-209.

41. Activate Networks I (2015) Who is central to a social network? It depends on your centrality measure.

42. Bakker HLM, De Kleijn JP (2014) Management of engineering projects-people are key, NAP Netwerk, Nijkerk, The Netherlands.

43. Morbach J, Hai R, Bayer B, Marquardt W (2008) Document models Collaborative and Distributed Chemical Engineering. From Understanding to Substantial Design Process Support pp.111-125.

44. Sieminski A (2013) International energy outlook 2013. US Energy Information Administration (EIA) Report Number: DOE/EIA-0484

45.WPC (2014) World Petroleum Council Guide: International Systems and Communications. 


\section{Civil Engineering Research Journal}

This work is licensed under Creative Commons Attribution 4.0 License

DOI:_10.19080/CERJ.2018.04.555637
Your next submission with Juniper Publishers will reach you the below assets

- Quality Editorial service

- Swift Peer Review

- Reprints availability

- E-prints Service

- Manuscript Podcast for convenient understanding

- Global attainment for your research

- Manuscript accessibility in different formats

( Pdf, E-pub, Full Text, Audio)

- Unceasing customer service

Track the below URL for one-step submission https://juniperpublishers.com/online-submission.php 